\title{
Disparities in Spawning Times Between in situ and ex situ Pillar Corals
}

\author{
Karen L. Neely ${ }^{1 *}$, Cindy L. Lewis ${ }^{2,3}$ and Kevin A. Macaulay ${ }^{1}$ \\ 1 Halmos College of Natural Sciences and Oceanography, Nova Southeastern University, Dania Beach, FL, United States, \\ ${ }^{2}$ Florida Keys Marine Laboratory, Long Key, FL, United States, ${ }^{3}$ Florida International University, Miami, FL, United States
}

\section{OPEN ACCESS}

Edited by:

Yehuda Benayahu,

Tel Aviv University, Israel

Reviewed by:

Charles Alan Jacoby,

St. Johns River Water Management

District, United States

Jessica Bouwmeester

Smithsonian Institution, United States

${ }^{*}$ Correspondence:

Karen L. Neely

kneelyo@nova.edu

Specialty section:

This article was submitted to

Coral Reef Research,

a section of the journal

Frontiers in Marine Science

Received: 12 December 2019

Accepted: 13 July 2020

Published: 11 August 2020

Citation:

Neely KL, Lewis CL and Macaulay KA (2020) Disparities in Spawning Times Between in situ

and ex situ Pillar Corals.

Front. Mar. Sci. 7:643.

doi: 10.3389/fmars.2020.00643
Contrasts in spawning time between in situ and ex situ colonies of the pillar coral Dendrogyra cylindrus were assessed by comparing 8 years of in situ spawning observations with 3 years of observations on ex situ corals held in outdoor flowthrough tanks. In situ colonies exhibited a 3-day spawning window, with peak spawning occurring three nights after the full moon and 90 (males) - 96 (females) min after sunset. The ex situ spawning window extended across 7 days, with a peak on nights $4-5$ after the full moon; females continued to spawn through night 8. Ex situ spawning occurred $\sim 50$ min later than in situ spawning, and the spawning window for ex situ females was significantly greater than for in situ colonies. Fragments held ex situ for as few as 10 days experienced delayed spawning times, but corals held for greater than one lunar year exhibited significantly later spawning than those held less than one lunar year. Early and late full moons resulted in earlier male spawn time and asynchronous gamete release between males and females. Comparing spawn times throughout the Caribbean identified distance from lighted shorelines as a strong correlate with spawn time in minutes after sunset; proximity to artificial light resulted in delayed spawn times. We propose that artificial lights are red-shifting the twilight spectrum and affecting corals' perception of lighting cues that trigger spawning. Coral colonies held at outdoor ex situ facilities, which are subject to even higher levels of artificial light, exhibit even further asynchrony in spawning time as well as spawning night. The effects of widespread and increasing light pollution on spawning synchrony may represent a potential stressor that could inhibit natural reef recovery.

Keywords: Dendrogyra cylindrus, pillar coral, spawning, light pollution, hermaphrodite, assisted reproduction

\section{INTRODUCTION}

Scleractinian corals are the building blocks of coral reefs, providing the habitat and ecological services that enable the persistence of the ecosystem and its diverse community. Slow-growing and long-lived, coral colonies can reproduce asexually through fragmentation (Highsmith, 1982) and also sexually through egg fertilization (Harrison and Wallace, 1990). Sexual reproduction is the only mechanism for corals to create the new genetic recombinations that sustain genotypic diversity and provide resiliency under current and future environmental conditions. In most stony coral species, this opportunity for sexual reproduction occurs only once a year.

The majority of reef-building Caribbean coral species rely on spawning to allow sperm and eggs to meet in the surrounding waters (Szmant, 1986). This synchronized release of gametes is 
governed by a suite of environmental cues that are known but not fully understood. These cues may include water temperature (Harrison et al., 1984), solar insolation (van Woesik et al., 2006), wind (van Woesik, 2010), lunar cycles (Richmond and Jokiel, 1984), and diel cycles (Brady et al., 2009). Genetic variability (Levitan et al., 2011) and chemical cues such as pheromones (Atkinson and Atkinson, 1992; Twan et al., 2003) also may play a role. Within Florida, spawning of most coral species can be relatively well predicted based on the month (July-September), date (nights after the full moon), and time (minutes before or after sunset).

Dendrogyra cylindrus is an uncommon but conspicuous stony coral species found on reefs throughout the Caribbean. In Florida, juveniles have not been observed (Miller, 2000), and the large distances between adults may prohibit fertilization, leaving the population reproductively extinct. As a result, efforts since 2012 have identified spawning times while collecting gametes for assisted fertilization and laboratory rearing. Day and time of D. cylindrus spawning were first identified and reported on in Florida (Neely et al., 2013, 2018) and Curacao (Marhaver et al., 2015). Subsequent events have been recorded in other regions of the Caribbean.

As a result of rapidly declining $D$. cylindrus populations in Florida, a genetic rescue project was initiated in 2015 to collect colony fragments and store them in onshore facilities for protection from thermal stress and disease. From 2015 to 2019, nearly 300 fragments representing 94 genotypes were collected and stored in outdoor raceways exposed to natural temperature and light cycles. Gametogenesis was considered to be possible, and these fragments were observed for spawning over multiple years.

This paper uses 8 years of in situ spawning observations to refine spawning times and assess causes of interannual variation. It also utilizes the significant differences in spawning times between in situ and ex situ colonies to suggest specific spawning cues for this species and identify barriers to synchronized gamete release in both in situ and ex situ populations.

\section{MATERIALS AND METHODS}

\section{In situ Observations}

For 8 years (2012-2019), divers recorded Dendrogyra cylindrus spawning at sites throughout the Florida Keys National Marine Sanctuary and Dry Tortugas National Park (Figure 1). Though spawning of $D$. cylindrus can occur from late July to October (Jordan, 2018), Florida efforts were conducted following the late July - mid August full moons. Sites ranged in depth from 4.3 to $10.4 \mathrm{~m}$. The number of colonies monitored varied by site, year, and sometimes by night during each year and at each site. We observed in situ spawning from 26 different genotypes [as identified by genetic sampling (Chan et al., 2019)]. For 10 of these genotypes, we observed gamete release during at least two different years. For 7 of the genotypes, we observed multiple ramets (clonal colonies produced by asexual fragmentation) spawning; the number of ramets varied between 2 and 100 .
We identified colonies using tags and/or photographs that allowed us to monitor known colonies over multiple nights or years. Each data record included: spawning start time, spawning end time, gender (release of eggs or sperm), and the percentage of the colony that spawned. The number of nights that we conducted observations varied by year and location (Table 1). Divers began observing colonies by $60 \mathrm{~min}$ after sunset (average: $45 \mathrm{~min}$ ) and concluded observations by $115 \mathrm{~min}$ after sunset if spawning was not observed. One exception was 2013 when divers did not begin observations until $85 \mathrm{~min}$ after sunset. In situ observations from the Dominican Republic, St. Croix, and Curacao were provided by local researchers.

\section{Ex situ Observations}

We monitored ex situ D. cylindrus fragments for spawning during 2016, 2017, and 2018. These fragments were collected between 25 January 2016 and 1 August 2018 as part of a genetic rescue project. The fragments observed to spawn represented 24 different genotypes and had been housed in land-based aquaria for 10-587 days before gamete release. Fragments were held and observed in raceways at two different facilities: Keys Marine Laboratory (KML) in the Middle Florida Keys and Mote Marine Laboratory (Mote) in the Lower Florida Keys.

At KML, corals were held in a flow-through seawater system drawn from a $10.7 \mathrm{~m}$ well. Water was passed through an airstripping (degassing) tower to remove residual hydrogen sulfide and aerate the water. Degassed water was recirculated through a heater/chiller system to maintain seasonal reef temperatures (winter: $25^{\circ} \mathrm{C} \pm 1^{\circ}$; summer: $28^{\circ} \mathrm{C} \pm 1^{\circ}$ ) before distribution to coral raceways. Between January and August, controlled temperatures were gradually increased from $25^{\circ} \mathrm{C} \pm 1^{\circ}$ to $28^{\circ} \mathrm{C} \pm 1^{\circ}$ to mimic ambient seasonal changes. Raceways were $40 \mathrm{~cm}$ deep. Corals were exposed to natural light cycles, but held under an $80 \%$ shade cloth to replicate light intensities consistent with 5-10 m reef depths.

At Mote, colonies were housed in a flow-through seawater mixture of $75 \%$ well water and $25 \%$ canal water. Well water was drawn from a $10.7 \mathrm{~m}$ well, filtered, and degassed. Air stones in each tank provided aeration and raised the $\mathrm{pH}$ of the water. Well water temperature was not manipulated and remained constant, but differences in air temperatures and the addition of seasonally changing canal water resulted in winter temperatures of $22.8-$ $25.1^{\circ} \mathrm{C}$ and summer temperatures of $25.1-27.8^{\circ} \mathrm{C}$. Raceways were 40-100 cm deep. Corals were exposed to natural light cycles, but held under a $70 \%$ shade cloth, with an additional $70 \%$ shade cloth added from 1200 to 0800 .

We observed ex situ corals during the potential spawning window of 2-8 nights after the full moons (NAFM) of July/August during 2016, 2017, and 2018. Due to the availability of fragments and observers, the number of nights of observation varied by year and facility. The number of observed fragments also varied by year, facility, and to a lesser extent, night within a spawning window. For a few observation nights, observers did not record the total number of observed fragments; the number is estimated based on the number recorded on previous and subsequent nights. All spawning fragments were identified 


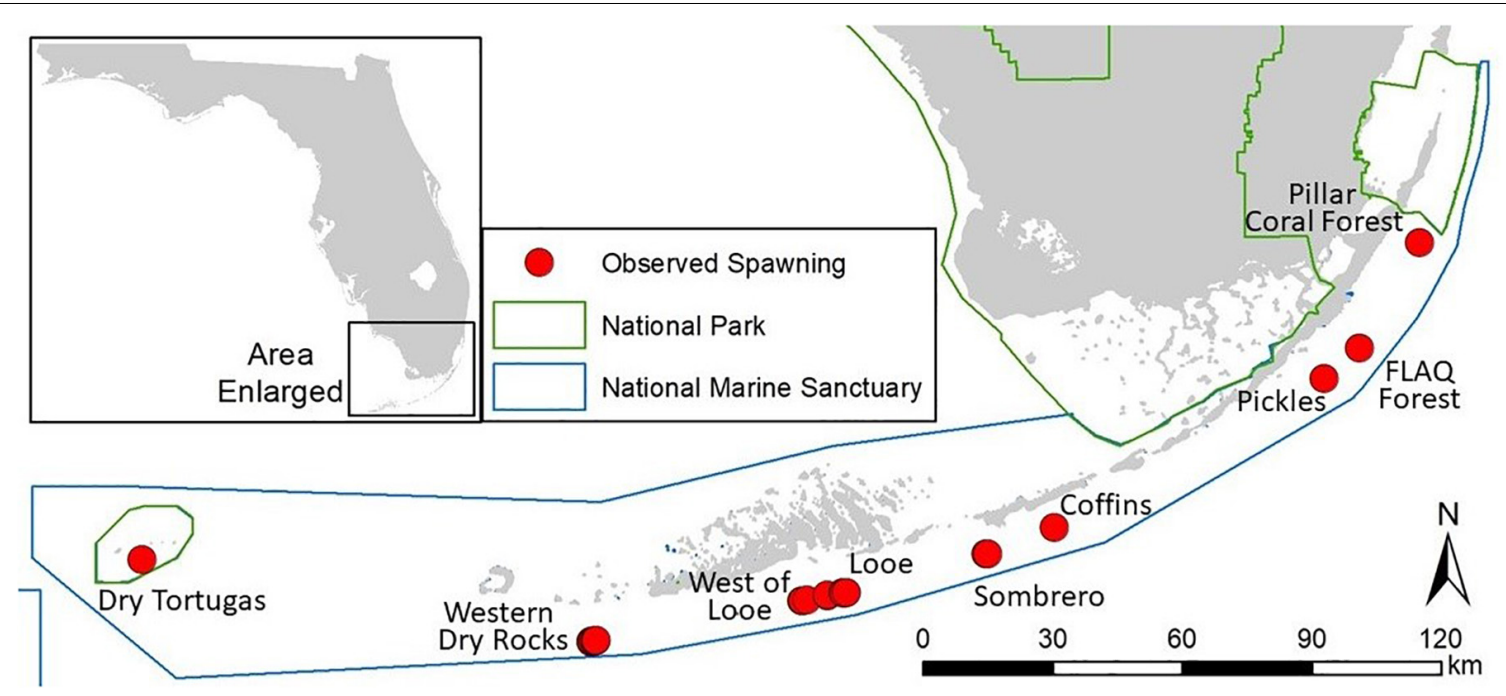

FIGURE 1 | Locations of 26 in situ Dendrogyra cylindrus genotypes observed spawning between 2012 and 2019 on the Florida Reef Tract.

to genotype based on identification tags. For some genotypes, multiple fragments were observed. For each spawning event, observers recorded fragment genotype, date, time of spawning, and gender.

\section{Statistical Analyses}

We referenced the spawning times of ex situ, Florida in situ, and Caribbean in situ colonies to solar and lunar cycles. We identified

TABLE 1 | Percentage of observed in situ Dendrogyra cylindrus colonies that spawned during each night after the full moon.

\begin{tabular}{|r|r|r|r|r|r|r|}
\hline \multirow{2}{*}{ Year } & \multirow{2}{*}{ Site (Sample Size) } & \multicolumn{5}{|c|}{ NAFM } \\
\cline { 3 - 7 } & & 1 & 2 & \multicolumn{1}{|c|}{3} & 4 & 5 \\
\hline 2012 & Pillar Coral Forest (many) & & & $50 \%$ & & \\
\hline 2013 & Pillar Coral Forest (many) & & & $30 \%$ & $70 \%$ & \\
\hline \multirow{2}{*}{2014} & Dry Tortugas (6-9) & $0 \%$ & $0 \%$ & $100 \%$ & $17 \%$ & \\
\cline { 2 - 7 } & Pillar Coral Forest (14-many) & & $10 \%$ & $50 \%$ & & \\
\hline \multirow{2}{*}{2015} & Dry Tortugas (8-9) & & & $100 \%$ & $0 \%$ & \\
\cline { 2 - 7 } & Coffins (27-many) & & & & $89 \%$ & $0 \%$ \\
\hline \multirow{3}{*}{2016} & FLAQ Forest (many) & & & $75 \%$ & & \\
\cline { 2 - 7 } & Pickles (many) & & & $100 \%$ & & \\
\cline { 2 - 7 } & Coffins (12) & & & $42 \%$ & & \\
\hline 2017 & Sombrero (4) & & & $100 \%$ & $75 \%$ & \\
\hline 2018 & Looe (7-12) & & $33 \%$ & $75 \%$ & $0 \%$ & \\
\hline 2019 & Lestern Dry Rocks (17) & & & $59 \%$ & $31 \%$ & \\
\hline & \# Genotypes Observed & 1 & 21 & 39 & 21 & 1 \\
\hline & \% Genotypes Spawning & $0 \%$ & $43 \%$ & $85 \%$ & $38 \%$ & $0 \%$ \\
\hline
\end{tabular}

Each row indicates a site with the sample size of the number of colonies observed. Some sites include multiple genotypes while others include multiple ramets within a genotype. At clonal sites, the number of colonies observed was not always quantified. In these cases, "some" has been estimated to $30 \%$, and "many" has been estimated to $75 \%$. Many individual colonies spawn over multiple nights and so values do not sum to $100 \%$. When no observations were conducted, cells are blank. The bottom two rows sum the number of genotypes observed on each night across all years and also the percentage of those genotypes that spawned on each night. spawning time as the number of minutes after local sunset. We identified spawning date using the number of nights after the full moon (NAFM). We defined the night of the full moon as the period of darkness closest to the local time of maximum lunar fullness. For example, a full moon at 0900 on 2 August would be attributed to 1 August; a spawning event occurring on the night of 4 August would thus be identified as occurring 3 NAFM.

To identify proximity to artificial light sources, we input GPS points from each spawning site (including ex situ fragments) into Google Earth and measured the distance to the nearest lighted building or road with streetlamps.

We compared spawning times in minutes after sunset between genders, years, and locations (in situ vs ex situ). When equal variance and Shapiro-Wilk normality tests passed, we analyzed comparisons with a Student's $t$-test (two-sample) or KruskalWallis one-way ANOVAs. Dunn's method pairwise comparisons were used to identify differences. When equal variance or normality failed, we used Mann-Whitney Rank Sum tests. We compared variance of spawning times (how dispersed spawning times were within the spawning windows) using Brown-Forsythe equal variance tests. For all tests, $\alpha=0.05$ was used as the threshold for significance.

\section{RESULTS}

\section{In situ Spawning Times}

In situ D. cylindrus colonies were observed spawning 2, 3, and 4 nights after the full moon (NAFM). Spawning was never observed on NAFM 1 or 5 ( $N=1$ observed genotype, but multiple ramets). Many colonies spawned over multiple nights. On NAFM 2 and 4, 43 and $38 \%$ of observed genotypes spawned, respectively; the proportion of clonal ramets observed spawning on NAFM 2 and 4 ranged from 10 to $89 \%$. On NAFM 3, 85\% of observed genotypes spawned, with the percentage of ramets spawning ranging from 30 to $100 \%$ (Table 1 ). 


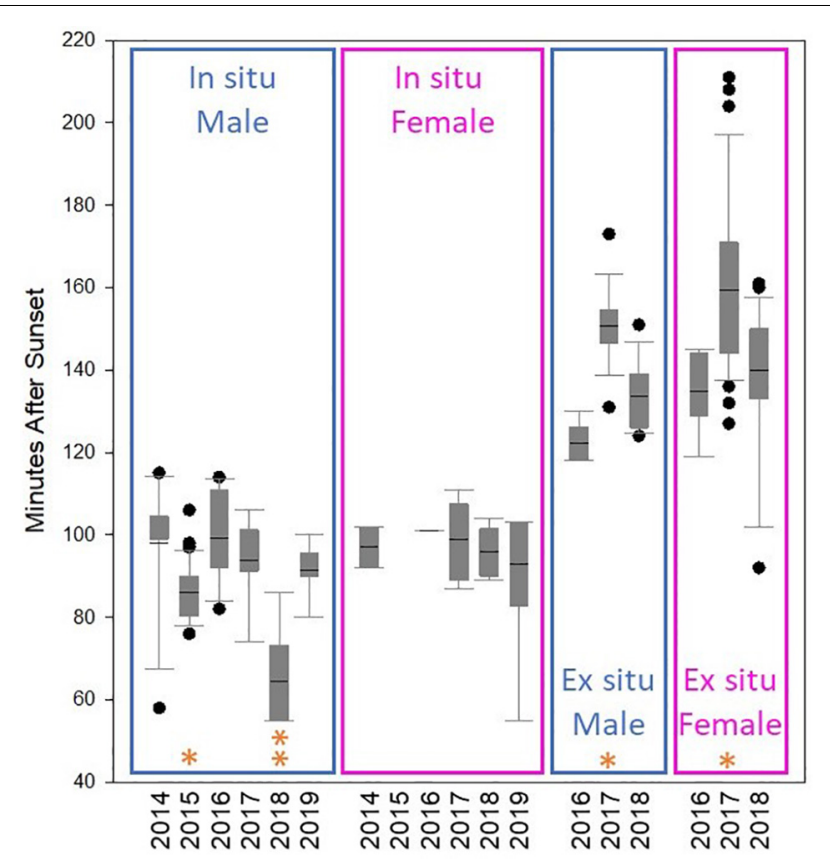

FIGURE 2 | Initial spawn time in minutes after sunset of in situ and ex situ Dendrogyra cylindrus colonies separated by year and by gender. Box plot metrics include: mean (black line), 25th-75th percentile (box), 10th-90th percentile (whiskers), and outliers (dots). In $2015\left(^{*}\right)$, in situ males spawned significantly earlier than in 2014 and 2016. In $2018\left(^{* *}\right)$, in situ males spawned significantly earlier than in 2014, 2016, 2017, and 2019. There were no significant differences in female spawn time among years. Among ex situ

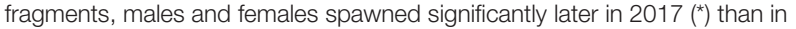
2016 and 2018

Across all years, in situ spawning occurred between 55 and $115 \mathrm{~min}$ after sunset (Figure 2). Average male spawn time (90 min after sunset) was significantly earlier than average female spawn time (96 min after sunset) (Mann-Whitney Rank Sum Test; $p<0.01)$. The variance in release times between males and females was not significantly different (Brown-Forsythe equal variance test).

Spawn times of males and females were compared between years. Shapiro-Wilk normality failed, and so Kruskal-Wallis oneway ANOVA on ranks followed by Dunn's Method pairwise comparisons were used to identify differences. Male spawn time in 2015 was significantly earlier than in 2014 and $2016(p<0.01)$. Male spawn time in 2018 was significantly earlier than in 2014, 2016, 2017, and 2019 ( $p<0.05$ ). In 2018, the average male spawn time (64 min after sunset) occurred 32 min earlier than the average female spawn time (96 min after sunset). The average difference in spawn time between males and females across all other years was only $4 \mathrm{~min}$. Female spawn time did not vary significantly across years.

\section{Ex situ Spawning Times}

Ex situ D. cylindrus spawned on NAFM 2 thru 8. The percentage of spawning colonies peaked on NAFM 5 at Mote in 2016 and 2017 (27 and 32\%, respectively) and on NAFM 4 at
TABLE 2 | Percentage of observed ex situ Dendrogyra cylindrus fragments that spawned on each night after the full moon (NAFM).

\begin{tabular}{|c|c|c|c|c|c|c|c|c|}
\hline \multirow{2}{*}{ Year } & \multirow{2}{*}{ Site (Sample Size) } & \multicolumn{7}{|c|}{ NAFM } \\
\hline & & 2 & 3 & 4 & 5 & 6 & 7 & 8 \\
\hline \multirow{2}{*}{2016} & Mote (many: 30) & $3 \%$ & $3 \%$ & $10 \%$ & $27 \%$ & $20 \%$ & $10 \%$ & \\
\hline & KML (75) & & $1 \%$ & $1 \%$ & & & & \\
\hline \multirow{2}{*}{2017} & Mote (many: 77) & $13 \%$ & $10 \%$ & $12 \%$ & $32 \%$ & $13 \%$ & $12 \%$ & $3 \%$ \\
\hline & KML (1-42) & $0 \%$ & $0 \%$ & $10 \%$ & $2 \%$ & & & \\
\hline 2018 (July) & KML (27) & $0 \%$ & $0 \%$ & $19 \%$ & & & & \\
\hline 2018 (Aug) & KML (45-69) & & $9 \%$ & $22 \%$ & $16 \%$ & $9 \%$ & $7 \%$ & \\
\hline \multicolumn{2}{|c|}{ \# Fragments Observed (est) } & 176 & 320 & 320 & 110 & 152 & 152 & 77 \\
\hline \multicolumn{2}{|r|}{ \% Fragments Spawning } & $1 \%$ & $5 \%$ & $11 \%$ & $25 \%$ & $13 \%$ & $10 \%$ & $3 \%$ \\
\hline
\end{tabular}

Each row includes the sample size of how many fragments were observed, but in two instances, the exact number was unknown, and values were assumed based on records from the adjacent nights. The bottom two rows sum the number of fragments observed on each night across all years (with estimates for the unknown nights included) and also the percentage of those fragments that spawned on each night.

KML in 2017, July 2018, and August 2018 (10, 19, and 22\%, respectively) (Table 2). At both facilities, females spawned over more nights than males, with only females spawning on NAFM 7 and 8 (Figure 3 ).

Time of ex situ spawning ranged from 87 to $211 \mathrm{~min}$ after sunset. Male spawning was significantly earlier (139 min after sunset) than female spawning (148 min after sunset) (MannWhitney Rank Sum Test; $p=0.01$ ). In 2017, both male and female ex situ average spawn times were significantly later than spawn times in 2016 and 2018 (one-way ANOVA with Holm-Sidak pairwise comparisons, $p<0.001$ ) (Figure 2).

\section{In situ vs ex situ Spawning}

Compared to in situ colonies, ex situ spawning: (1) exhibited a delay in peak spawning night, (2) ranged over a greater number of spawning nights, (3) occurred later in the evening, and (4) spanned a greater time period in females (Figure 4).

Spawning peaked on NAFM 3 for in situ colonies and on NAFM 4 and 5 for ex situ fragments. Spawning was not observed after NAFM 4 in situ, but occurred as late as NAFM 8 in ex situ fragments, though only by females during NAFM 7 and 8 .

Ex situ corals spawned on average $52 \mathrm{~min}$ (female) and 49 min (male) later than in situ colonies. These differences were significant for both sexes (Females: Mann-Whitney Rank Sum Test; $p<0.001$. Males: $t$-test; $p<0.001)$.

The range of spawning times was not the same when compared between genders or in situ/ex situ status. Standard deviation of male spawn time was the same in both ex situ and in situ colonies (13 min). In situ female spawn time had a similar standard deviation (12 min), even with the inclusion of one anomalous egg release on NAFM 4 in 2019 that occurred 28 min earlier than any other female spawn. However, ex situ females released over a longer timeframe (standard deviation: $23 \mathrm{~min}$ ). Tests of equal variance determined that variance was not significantly different between in situ males, in situ females, and ex situ males. However, ex situ females did have significantly greater variance than in situ females and in situ males (BrownForsythe test; $p<0.05$ ).

The spawn times of ex situ colonies were compared with the length of time that fragments had been in onshore systems. 


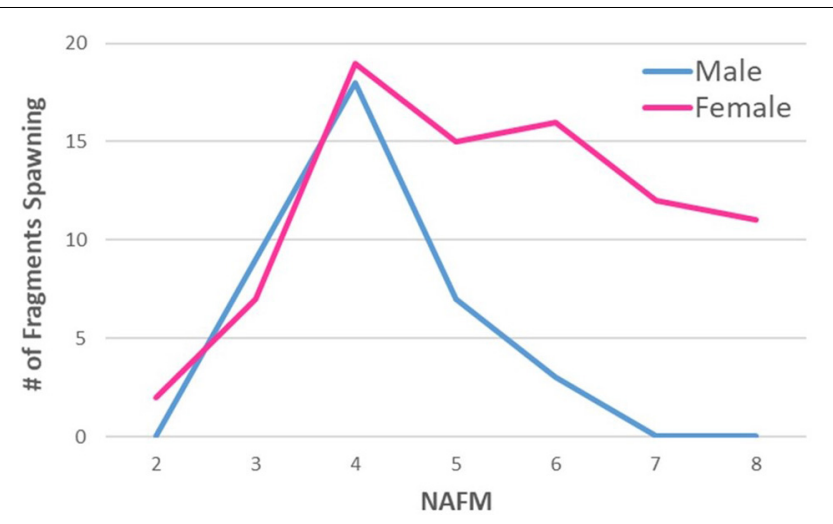

FIGURE 3 | Number of ex situ Dendrogyra cylindrus fragments spawning on each night after the full moon (NAFM). Numbers are summed across two facilities and all years of observation. Male spawning peaked on NAFM 4 and decreased to zero by NAFM 7. Female spawning continued through NAFM 8.

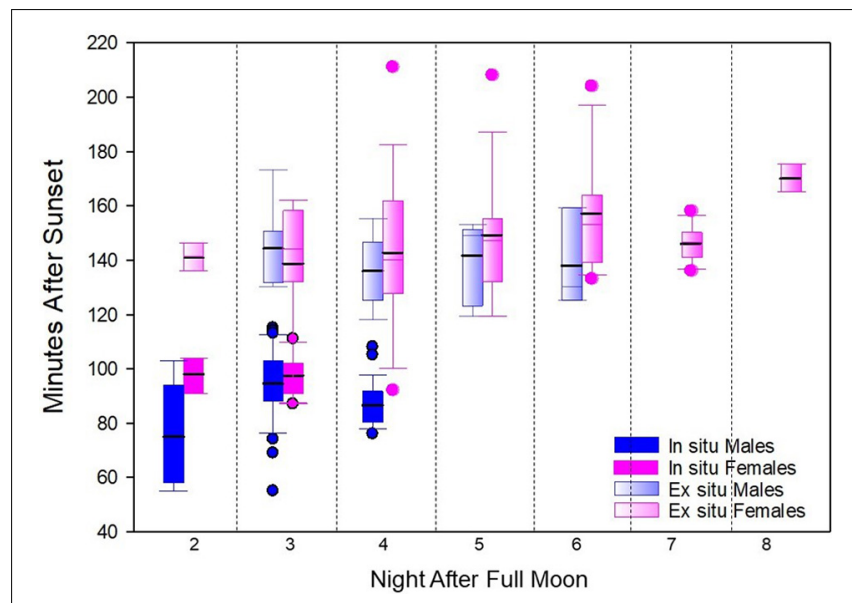

FIGURE 4 | Spawn times in minutes after sunset of in situ and ex situ Dendrogyra cylindrus separated by night of spawning. Box plot metrics include: mean (black line), 25th-75th percentile (box), 10th-90th percentile (whiskers), and outliers (dots). Ex situ corals released later in the evening and on a greater number of nights than in situ corals.

Because collections occurred over many years as part of a genetic rescue project, spawning corals lived in onshore raceways from 10 to 561 days before spawning. Even corals that had been collected as few as 10-15 days before spawning released gametes $23-48 \mathrm{~min}$ later than the average in situ time (Figure 5). Increased holding time in onshore raceways correlated with later spawn times for both males and females (Linear Regression. Females: $R^{2}=0.19$, $p<0.001$. Males: $\left.R^{2}=0.36, p<0.001\right)$. For females, individuals that spawned after being onshore for more than one lunar year released eggs an average of 17 min later than those held less than one lunar year (Mann-Whitney Rank Sum Test; $p=0.002$ ). For males, average spawn time of fragments held longer than one lunar year was 14 min later than those held less than one lunar year $(t$-test; $p=0.007)$.

Ten different genotypes were observed spawning both ex situ and in situ (within the same year and also across years). Ex situ fragments of these genotypes had been held between 20

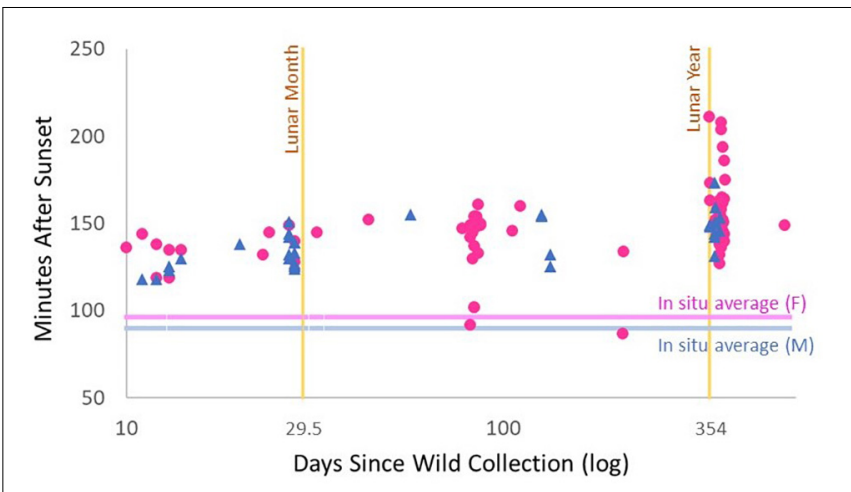

FIGURE 5 | Spawning time (minutes after sunset) of ex situ Dendrogyra cylindrus fragments compared to number of days held ex situ (logarithmic scale). Female spawn times are pink circles; male spawn times are blue triangles. Pink and blue horizontal lines indicate the average spawn time of in situ colonies from 2012 to 2018 . The yellow vertical bar on the left indicates one lunar month (29.5 days); the yellow vertical bar on the right indicates one lunar year (354 days).

and 387 days. Eight of the genotypes were observed spawning within the first year of holding. Four of the genotypes (including two observed spawning during year one), spawned after being held onshore for longer than a year. Two of these (West of Looe 5, West of Looe 2) were first observed spawning during their second year of holding, and their egg releases were among the latest of any fragments. The other two (Looe B9, Looe 3) were observed spawning over 2 years. Both genotypes spawned later during the second year than the first, but the differences were not significant (Mann-Whitney Rank Sun Test). One genotype (Sombrero 2-3) was observed spawning ex situ in both July and August 2018. Spawn time in August was earlier, but was male while the July release was female. Across all genotypes, ex situ spawning occurred later than in situ spawning (Figure 6). For the five genotypes in which multiple observations allowed for statistical analyses, these ex situ versus in situ differences were significant ( $t$-test; $p<0.05$ ).

\section{Hermaphroditism}

Past reports of D. cylindrus hermaphroditism include simultaneous egg and sperm release from different pillars of a single colony and also switches in colony gender between years (Neely et al., 2013). Observations here expanded these observations of hermaphrodism to include additional genets. Of the 29 genets observed over multiple nights, years, or environments (in situ vs ex situ), 11 (38\%) exhibited at least one form of hermaphroditism. Of these 11 genotypes, 1 simultaneously spawned both eggs and sperm for three consecutive years, 7 spawned as different genders on different nights during the same year, and 8 spawned as different genders between years. Intra-year and inter-year hermaphroditism occurred in situ as well as ex situ. Of those that switched gender between years, four switched from males to hermaphrodites, three switched from females to males, and one switched from hermaphrodite to male. 


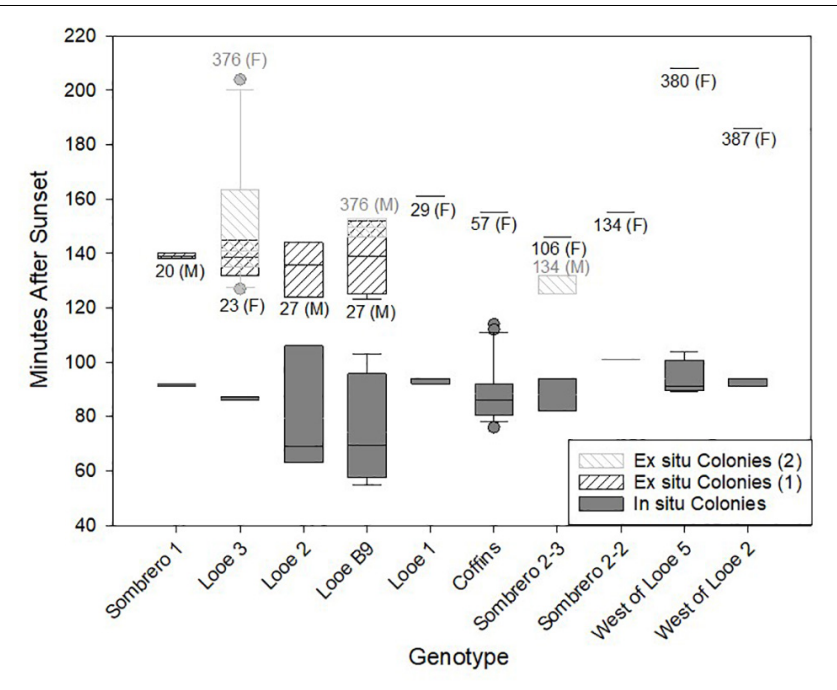

FIGURE 6 | Spawning times (minutes after sunset) of Dendrogyra cylindrus genotypes observed both in situ (solid gray) and ex situ (hashed). The number of days held ex situ and the gender (M/F) are indicated beneath the ex situ box plots. For three genotypes, multiple ex situ spawning events were observed and separated by shading. Genotype Sombrero 2-3 spawned during two consecutive months and switched genders. Genotypes Looe 3 and Looe 2 spawned in both 2017 and 2018. For all three of these, the second spawning event (2) is indicated by the lighter crosshatch.

\section{DISCUSSION}

\section{In situ Spawning}

Spawning time of in situ Florida Keys D. cylindrus colonies is highly predictable, exhibiting a narrow range by date (2-4 NAFM) and by time of night (55-115 min after sunset). This contrasts with other well studied Caribbean corals that have a much greater

range in spawning times. As examples, Caribbean acroporids have an in situ spawning window of up to 14 nights (Fogarty et al., 2012). Orbicella faveolata and Montastraea cavernosa spawn within a small window of nights, but the nightly window spans up to $4 \mathrm{~h}$ (Jordan, 2018).

Despite their concentrated spawning window, the time of night that $D$. cylindrus colonies spawn varies throughout the Caribbean, even when standardized to local sunset time. Spawning times of Florida Keys colonies were compared with those from Curaçao (2012-2016), Dominican Republic (20172019), and St. Croix (2019) (Figure 7). Within all regions, the interval between male and female spawn times averaged 6.5$13 \mathrm{~min}$. However, the region of earliest spawn time (Florida) averaged $32 \mathrm{~min}$ (males) and $37 \mathrm{~min}$ (females) earlier than the region with the latest spawn time (Curaçao Sea Aquarium).

Across all years, female spawn time in Florida remained constant. However, male spawn time varied significantly across years, and variations correlated with the date of the full moon. The dates of the full moons that triggered spawning from 2012 to 2019 were averaged to identify August 8 as the mean full moon date. Each year's full moon date was then compared against this mean and plotted against D. cylindrus spawn time (Figure 8). The years with significantly earlier male spawn times (2015 and 2018) were also the years with notably early full moons ( 9 nights and 12 nights before the mean). In 2013, the full moon was notably later (12 nights) than the mean date. Correspondingly, male spawn time in 2013 was also earlier than the average spawn time, although these values are excluded from formal analyses because sperm release was already underway when divers entered the water. In summary, male spawn times during years when the full moon varied from -7 to +10 days from the average were nearly synchronous. At dates before or after that, male spawning occurred earlier.

The same pattern of deviation in male spawn time occurred within the Dominican Republic. Female spawn times were
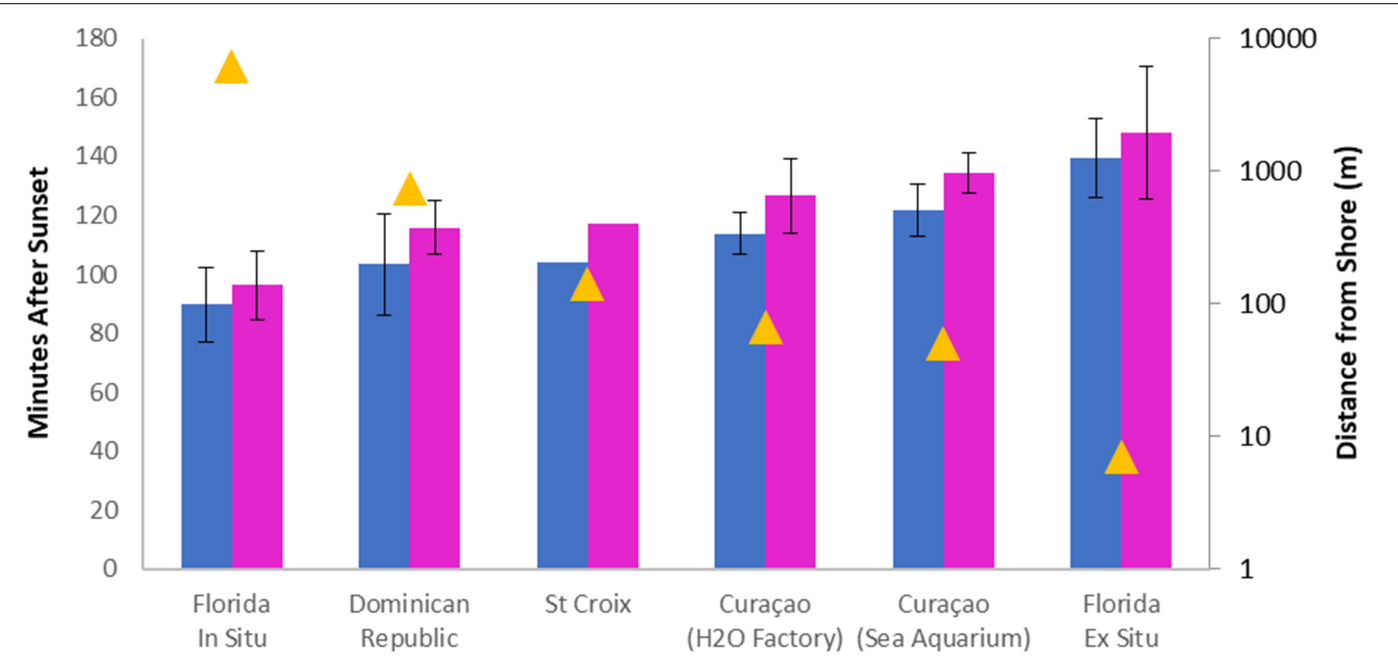

FIGURE 7 | Spawn times (minutes after sunset) of Dendrogyra cylindrus at different sites. Sexes are represented by color (males: blue, females: pink). Error bars show standard deviation. Yellow triangles represent the minimum distance of spawning sites from the nearest onshore building (note logarithmic scale). The difference in spawning time between males and females is constant across sites, but proximity to artificial lights shifts spawning times later in the night $\left(R^{2}>0.9, p<0.005\right)$. 


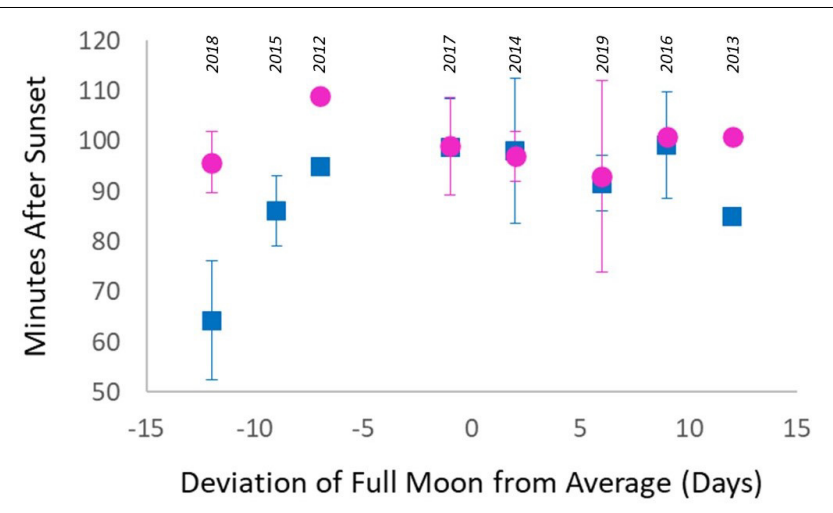

FIGURE 8 | Spawn time (minutes after sunset) of Dendrogyra cylindrus plotted against the relative date of the full moon in comparison with the 8-year average (2012-2019). Pink circles represent average female spawn times, blue squares are average male spawn times, and error bars show standard deviations. The datapoint for male spawn time in 2013 indicates the earliest confirmed observation, but many males had already spawned at an unknown interval before this. Spawn times between males and females closely align near the lunar average, but male spawn time is earlier as the full moon deviates from the average.

consistent from 2017 to 2019. But male spawn time was significantly earlier in 2018 (95 min after sunset) than in 2017 (114 min) and 2019 (119 min) (ANOVA with HolmSidak comparisons; $p<0.05)$. The consistent pattern of female synchrony and male asynchrony across years in both Florida and the Dominican Republic colonies indicates a physiological mechanism rather than a localized environmental or genotypic one. Gametogenesis of D. cylindrus begins in May for females and mid-June for males (Szmant, 1986). For sperm, this developmental window is less than 2 months. Shortening or lengthening that window by more than 7 days via an abnormally early or late full moon could lead to overdeveloped or, particularly, underdeveloped sperm that are unable to release at the proper time. While the rate of decline in sperm viability after spawning and the health status of sperm released over different years are unknown, both could negatively impact fertilization rates when the time between spawning and fertilization is increased.

\section{Ex situ Spawning}

Fragments from a range of sizes spawned ex situ, including several fragments with a maximum linear dimension of less than $6 \mathrm{~cm}$. These small fragments were all formerly pieces of older larger colonies, though many were isolates that had been disconnected from other live tissue for multiple years. This indicated that the size required for gametogenesis, at least for fragments or isolates of older colonies, is quite small. It is unknown whether sexually produced juveniles would need to reach a larger minimum size to be reproductively mature.

Several fragments spawned after more than 1 year of being held ex situ. Thus, corals held in outdoor facilities, even without a supply of reef water, can continue to receive the appropriate environmental cues to initiate and complete gametogenesis.

\section{Hermaphroditism}

Known incidences of hermaphroditism in D. cylindrus continue to increase. Once thought to be a gonochoric species (Szmant, 1986), hermaphroditism has since been found within ramets of a single genet and also within single ramets (Neely et al., 2018). Histological studies have documented further instances of simultaneous hermaphroditism (Kabay, 2016). The observations presented here of numerous genotypes over space (ramets both in situ and ex situ) and time (observations over multiple nights and multiple years) expand the known incidence and spatial scale of that hermaphroditism. These data on Florida Keys colonies since 2012 show hermaphroditism to occur in at least $35 \%$ of the population's genotypes. This is likely a conservative estimate as sequential hermaphroditism across years would require multiple annual observations, which occurred on only a subset of the in situ genotypes. No regular patterns relating to colony size, health condition, or environmental variables indicate what may drive gender switches within or between ramets.

\section{In situ vs ex situ Spawning}

Spawning times of ex situ D. cylindrus fragments at the two outdoor holding facilities were more varied and less predictable than in situ spawn times. Ex situ corals spawned significantly later (51-53 min) than in situ corals and over an extended number of nights. The variance in spawning time of ex situ females was also greater than that of in situ females. These patterns held even for genotypes that were observed spawning both in situ and ex situ. Potential hypotheses for this include: (1) differences in chemical cues between in situ and ex situ environments, and (2) differences in light cues between in situ and ex situ environments.

Chemical cues, particularly sex steroids, have been proposed as environmental triggers for coral mass spawning events (Twan et al., 2003). Specifically, intraspecific cues released during male spawning could trigger female spawning. However, both in situ and ex situ observations for D. cylindrus refute this hypothesis. During the 4 years in which the moon was between -2 and +10 days from its mean date, the interval between male and female spawn times averaged less than $2 \mathrm{~min}$, and in some instances, females spawned before males. Further, in situ D. cylindrus female colonies spawning in Florida were on average $597 \mathrm{~m}$ (range: 2-4,300 $\mathrm{m}$ ) away from the nearest male colony, a prohibitive distance for transmission of these cues over such time frames. Additionally, the earlier male spawn times in 2015 and 2018 were not accompanied by earlier female spawn times as would be expected if male pheromones were the spawning cue. In ex situ facilities, females spawning in buckets or tanks isolated from other individuals did so within the time range of females exposed to spawning males. These data all indicate that $D$. cylindrus female spawning is not dependent upon or cued by male spawning. Interspecific cues are more difficult to identify. However, in situ colony conditions varied widely in geography, habitat type, and surrounding species composition, but did not vary significantly in spawn times. Likewise, the two ex situ facilities had dissimilar water sources, algal communities, and maintenance snails in their tanks, but did not vary in their spawn times. Synchronized spawning of other coral species has been replicated in artificial seawater (Craggs et al., 2017), and in 
2019 this was also achieved for D. cylindrus at Florida Aquarium's Center for Conservation, Apollo Beach, FL (K. Oneil, personal communication). We thus conclude that chemical cues from intra- or interspecific reef organisms are not driving spawn times.

The alternate hypothesis is that light cues are the proximal trigger for spawning, and that the differences in light experienced by ex situ and in situ colonies result in delayed ex situ spawn time. The role of the full moon in cueing the night(s) of spawning is established across many coral species (Richmond and Jokiel, 1984; Babcock et al., 1994) and confirmed by consistent NAFM spawning patterns by $D$. cylindrus across years and regions. However, moonrise is not the cue for spawn time within a night. Moonrise occurs approximately 35 min later each subsequent night after the full moon, but spawn time is consistent across NAFM. For D. cylindrus, which spawn early in the night compared with many other coral species, their spawn time sometimes occurs before and sometimes after moonrise. For example, Dendrogyra cylindrus colonies that spawn at the Florida average of 89-98 min after sunset on NAFM 2 release gametes after moonrise (e.g., August 2018: moonrise was 63 minutes after sunset), but by NAFM 3 and on subsequent nights, spawning occurs before moonrise (e.g., August 2018: NAFM 3 and 4, moonrise was 98 and 132 minutes after sunset, respectively), but by NAFM 3 and on subsequent nights, moonrise occurs after spawning (August 2018: NAFM $3=98 \mathrm{~min}$. NAFM $4=132 \mathrm{~min}$ ).

The more predictive cue for spawn time within a night is time of sunset. In our study, fragments of $D$. cylindrus brought to ex situ facilities within 15 days of spawning released gametes $50 \mathrm{~min}$ later than those remaining in the wild. Similarly, experiments on another Caribbean coral species, Orbicella franksii, showed that experimentally manipulating sunset time affected spawn time even for corals collected within $12 \mathrm{~h}$ of spawning (Brady et al., 2009). These corals are not releasing gametes based on longterm circadian rhythms, but directly cueing on sunset time on the night of spawning.

The timing of male and female gamete release needs to be precise for a coral species to achieve successful fertilization (Oliver and Babcock, 1992). And yet perception of precise sunset time as a change in light intensity (lumens), particularly underwater, can be affected by numerous factors, including depth, turbidity, sea state, overcast skies, and clouds on the horizon. In spite of these factors, in situ D. cylindrus colonies spawned consistently regardless of depth, sea state, or weather conditions. While light intensity would be affected by these factors, the wavelengths would not. Sweeney et al. (2011) measured light spectra on nights surrounding the full moon; on nights before and including the full moon, illuminance from the moon results in a red-shifted spectrum following sunset. In subsequent nights when the moon rises later, the postsunset spectrum is markedly more blue-shifted. Sweeney et al. also noted that, while light intensity was diminished in cloudy conditions, spectral composition remained relatively constant. As such, corals utilizing spectral cues rather than light intensity cues would consistently perceive lunar and solar patterns regardless of overcast skies or apparent differences in sunset time due to weather or water conditions. Work by Sweeney et al. predicted that corals that could detect spectral peaks at 434 and $546 \mathrm{~nm}$ would best discriminate these twilight spectra. They further propose a thresholding mechanism by which opponency between these two peaks could initiate spawning. Physiological work has identified photoreceptors in corals that can detect this spectral range (Gorbunov and Falkowski, 2002; Levy et al., 2007), with Gorbunov and Falkowski (2002) identifying maximum sensitivity at $480 \mathrm{~nm}$ and a spectral band halfwidth of $110 \mathrm{~nm}$. Levy et al. (2007) also identified blue-light photoreceptors and further found that expression of cryptochrome genes increased on full moon nights as compared to new moon nights.

Corals using spectral changes during twilight as a spawning cue would be highly affected by the interference of artificial light. Johnsen et al. (2006) measured evening light spectra; they found that sunset and twilight spectra peaked at $450 \mathrm{~nm}$, fullmoon spectra were red-shifted to $500-700 \mathrm{~nm}$, and artificial light spectra peaked at $590 \mathrm{~nm}$. Artificial light spectra were further quantified; LED streetlights had bimodal peaks around 460 and $590 \mathrm{~nm}$, ceramic metal halides had bi-modal peaks at 520 and $600 \mathrm{~nm}$, and both low and high pressure sodium lights peaked around $590 \mathrm{~nm}$ (Tamir et al., 2017). These values indicate that artificial light after sunset mimics lunar spectra, which would prevent corals from identifying the blue spectra associated with the delayed moonrise on nights following the full moon.

Artificial light levels continue to increase with population and development. Tamir et al. (2017) measured anthropogenic light pollution (589 $\mathrm{nm}$ ) across water depth and distance from shore; they found that irradiance filters out quickly with depth and eliminated by $20 \mathrm{~m}$, but extends several kilometers from shore. Though some remote reefs may be spared this light pollution, reefs accessible by researchers for spawning work are generally close to populated and electrified infrastructure. However, even among regions where D. cylindrus spawning has been recorded, distance from artificial land-based structures (roads or buildings) varies greatly. All of the Florida observations occurred at least $6 \mathrm{~km}$ from shore; in contrast, the Curacao observations were less than $100 \mathrm{~m}$ from populated shorelines. The Dominican Republic and St. Croix observations were taken at intermediate distances. When spawn time (minutes after sunset) is compared with log distance from lighted structures from each site, correlations are highly significant for both males $\left(R^{2}=0.90 . p=0.004\right)$ and females $\left(R^{2}=0.95, p<0.001\right)$ (Figure 7).

Florida's ex situ D. cylindrus colonies experienced more artificial light pollution than even the most nearshore in situ Caribbean sites. In addition to close and regular proximity to lights on surrounding buildings, the shallow water depth of holding tanks filtered less red light than the deeper waters of in situ colonies. As a result, we propose that ex situ corals could not precisely detect the blue-shift in spectra associated with the time between sunset and moonrise. The reduced ability to perceive this cue limited the corals' ability to discern which NAFM it was, and also to clearly identify the time of sunset. As a result, spawning was scattered over many more NAFM and also extended later in the night. Females may have different sensitivity to these cues than males. This was evidenced by their extended number of spawning nights, larger variance in release time, and increased variance and delay in spawning time as their holding time in the onshore systems increased. A physiological 
mechanism for this sensitivity is unknown, but worth further consideration. Such physiological studies could be compared with experimental manipulations of light wavelengths to better identify the wavelengths and potentially the intensities associated with altered spawning behaviors.

These results suggest that in addition to the other stressors coral reefs are experiencing, light pollution may impact their spawning abilities. Though Dendrogyra cylindrus colonies within each site spawned in synchrony with each other, any potential for fertilization of gametes between sites experiencing different light regimes (particularly inshore to offshore) would be diminished as a result of asynchronous spawn times. If, as in the case of ex situ corals, light pollution is severe enough to not only delay but to confuse the spawning cues, reproduction within a site could be asynchronous, expanding over additional NAFM and through larger post-sunset timeframes. Peak fertilization in other Caribbean coral species has been shown to associate with the mean spawning time; those spawning early or late had reduced fertilization success (Levitan et al., 2004). Increases in spawning variances will likely have negative repercussions for sexual reproduction and natural replenishment of threatened D. cylindrus in the Caribbean and other reef-building corals around the world.

\section{DATA AVAILABILITY STATEMENT}

The datasets generated for this study are available on request to the corresponding author.

\section{AUTHOR CONTRIBUTIONS}

KN coordinated the field observations and Mote lab observations with participation by CL and KM. CL primarily coordinated the

\section{REFERENCES}

Atkinson, S., and Atkinson, M. J. (1992). Detection of estradiol-17 $\beta$ during a mass coral spawn. Coral Reefs 11, 33-35. doi: 10.1007/bf00291932

Babcock, R. C., Wills, B. L., and Simpson, C. J. (1994). Mass spawning of corals on a high latitude coral reef. Coral Reefs 13, 161-169. doi: 10.1007/bf00301193

Brady, A., Hilton, J., and Vize, P. (2009). Coral spawn timing is a direct response to solar light cycles and is not an entrained circadian response. Coral Reefs 28, 677-680. doi: 10.1007/s00338-009-0498-4

Chan, A. N., Lewis, C. L., Neely, K. L., and Baums, I. B. (2019). Fallen pillars: the past, present, and future population dynamics of a rare, specialist coral-algal symbiosis. Front. Mar. Sci. 6:218. doi: 10.3389/fmars.2019.00218

Craggs, J., Guest, J. R., and Davis, M. (2017). Inducing broadcast coral spawning. Ecol. Evol. 7, 11066-11078. doi: 10.1002/ece3.3538

Fogarty, N. D., Vollmer, S. V., and Levitan, D. R. (2012). Weak prezygotic isolating mechanisms in threatened Caribbean acropora corals. PLoS One 7:e30486. doi: 10.1371/journal.pone.0030486

Gorbunov, M. Y., and Falkowski, P. G. (2002). Photoreceptors in the cnidarian hosts allow symbiotic corals to sense blue moonlight. Limnol. Oceanogr. 47, 309-315. doi: 10.4319/lo.2002.47.1.0309

Harrison, P., and Wallace, C. (1990). Coral reproductive biology. Ecosyst. World 25, 132-207.

Harrison, P. L., Babcock, R. C., Bull, G. D., Oliver, J. K., Wallace, C. C., and Willis, B. L. (1984). Mass spawning in tropical reef corals. Science 223, 1186-1189. doi: $10.1126 /$ science. 223.4641 .1186
Keys Marine Lab observations with participation by $\mathrm{KN}$ and KM. KN conducted the analyses primarily. KM provided the insight on contributions of light. KN conducted the manuscript preparation, with input from CL and KM. All authors contributed to the article and approved the submitted version.

\section{FUNDING}

Funding for these activities was provided by NOAA's Coral Reef Conservation Program, US Fish and Wildlife Service grants program, Florida's Wildlife Legacy Initiative, and a donation by Bruce Hultgren.

\section{ACKNOWLEDGMENTS}

Field work observations were provided in part by Florida Fish and Wildlife Research Institute, Florida Aquarium, Keys Marine Laboratory, Coral Restoration Foundation, Florida Keys National Marine Sanctuary, Penn State University, Dry Tortugas National Park, Florida Keys Community College, and volunteers. Laboratory husbandry and observations were conducted in part by Mote Marine Laboratory, Keys Marine Laboratory, Florida International University, SUNY at Buffalo, Florida Aquarium, Florida Keys Community College, and volunteers. Data from the Dominican Republic were provided by M. Villalpando (FUNDEMAR - Dominican Republic). Data from St. Croix were provided by A. Lillis (The Nature Conservancy - St. Croix). Data from Curacao were provided by K. Marhaver (CARMABI) and by SECORE and were compiled by N. Fogarty and A. Jordan. Work was conducted in the Florida Keys National Marine Sanctuary under permits FKNMS-2013-085, FKNMS-2015-080, FKNMS2016-062 and in Dry Tortugas National Park under permit DRTO-2015-SCI-0018.

Highsmith, R. C. (1982). Reproduction by fragmentation in corals. Mar. Ecol. Prog. Ser. 7, 207-226. doi: 10.3354/meps007207

Johnsen, S., Kelber, A., Warrant, E., Sweeney, A. M., Widder, E. A., Lee, R. L., et al. (2006). Crepuscular and nocturnal illumination and its effects on color perception by the nocturnal hawkmoth Deilephila elpenor. J. Exper. Biol. 209, 789-800. doi: 10.1242/jeb.02053

Jordan, A. C. (2018). Patterns in Caribbean Coral Spawning. Florida: Nova Southeastern University.

Kabay, L. (2016). Population Demographics and Sexual Reproduction Potential of the Pillar Coral, Dendrogyra cylindrus, on the Florida Reef Tract, Halmos College of Natural Sciences and Oceanography. Florida: Nova Southeastern University.

Levitan, D., Fukami, H., Jara, J., Kline, D., McGovern, T., McGhee, K., et al. (2004). Mechanisms of reproductive isolation among sympatric broadcast-spawning corals of the Montastraea annularis species complex. Evolution 58, 308-323. doi: 10.1111/j.0014-3820.2004.tb01647.x

Levitan, D. R., Fogarty, N. D., Jara, J., Lotterhos, K. E., and Knowlton, N. (2011). Genetic, spatial, and temporal components of precise spawning synchrony in reef building corals of the Montastraea annularis species complex. Evolution 65, 1254-1270. doi: 10.1111/j.1558-5646.2011. 01235.x

Levy, O., Appelbaum, L., Leggat, W., Gothlif, Y., Hayward, D. C., Miller, D. J., et al. (2007). Light-responsive cryptochromes from a simple multicellular animal, the coral Acropora millepora. Science 318, 467-470. doi: 10.1126/science.11 45432 
Marhaver, K. L., Vermeij, M. J. A., and Medina, M. M. (2015). Reproductive natural history and successful juvenile propagation of the threatened Caribbean pillar coral Dendrogyra cylindrus. BMC Ecol. 15:9. doi: 10.1186/s12898-0150039-7

Miller, S. M. (2000). Quick Look Reports and Data Summaries. Key Largo, FL: UNCW.

Neely, K. L., Lewis, C., Chan, A., and Baums, I. B. (2018). Hermaphroditic spawning by the gonochoric pillar coral Dendrogyra cylindrus. Coral Reefs 37, 1087-1092. doi: 10.1007/s00338-018-1730-x

Neely, K. L., Lunz, K. S., and Macaulay, K. A. (2013). Simultaneous gonochoric spawning of Dendrogyra cylindrus. Coral Reefs 32, 813-813. doi: 10.1007/ s00338-013-1034-0

Oliver, J., and Babcock, R. (1992). Aspects of the fertilization ecology of broadcast spawning corals: sperm dilution effects and in situ measurements of fertilization. Biol. Bull. 183, 409-417. doi: 10.2307/1542017

Richmond, R. H., and Jokiel, P. L. (1984). Lunar periodicity in larva release in the reef coral Pocillopora damicornis at Enewetak and Hawaii. Bull. Mar. Sci. 34, $280-287$.

Sweeney, A. M., Boch, C. A., Johnsen, S., and Morse, D. E. (2011). Twilight spectral dynamics and the coral reef invertebrate spawning response. J. Exp. Biol. 214, 770-777. doi: 10.1242/jeb.043406

Szmant, A. M. (1986). Reproductive ecology of Caribbean reef corals. Coral Reefs 5, 43-53. doi: 10.1007/bf00302170
Tamir, R., Lerner, A., Haspel, C., Dubinsky, Z., and Iluz, D. (2017). The spectral and spatial distribution of light pollution in the waters of the northern Gulf of Aqaba (Eilat). Sci. Rep. 7:42329.

Twan, W.-H., Hwang, J.-S., and Chang, C.-F. (2003). Sex steroids in scleractinian coral, Euphyllia ancora: implication in mass spawning. Biol. Reprod. 68, 22552260. doi: 10.1095/biolreprod.102.012450

van Woesik, R. (2010). Calm before the spawn: global coral spawning patterns are explained by regional wind fields. Proc. R. Soc. B Biol. Sci. 277, 715-722. doi: 10.1098/rspb.2009.1524

van Woesik, R., Lacharmoise, F., and Köksal, S. (2006). Annual cycles of solar insolation predict spawning times of Caribbean corals. Ecol. Lett. 9, 390-398. doi: $10.1111 /$ j.1461-0248.2006.00886.x

Conflict of Interest: The authors declare that the research was conducted in the absence of any commercial or financial relationships that could be construed as a potential conflict of interest.

Copyright (c) 2020 Neely, Lewis and Macaulay. This is an open-access article distributed under the terms of the Creative Commons Attribution License (CC BY). The use, distribution or reproduction in other forums is permitted, provided the original author(s) and the copyright owner(s) are credited and that the original publication in this journal is cited, in accordance with accepted academic practice. No use, distribution or reproduction is permitted which does not comply with these terms. 